\title{
EPISTAXIS- AN ANALYTICAL STUDY IN TERTIARY REFERRAL HOSPITAL
}

\author{
T. V. S. S. N. Leela Prasad ${ }^{1}$, P. Rambabu², S. Suryaprakasa Rao 3 , K. Ravi Kumar ${ }^{4}$
}

${ }_{1}^{1}$ Assistant Professor, Department of ENT, Andhra Medical College, Visakhapatnam.

${ }^{2}$ Assistant Professor, Department of ENT, Andhra Medical College, Visakhapatnam.

3Professor, Department of ENT, Andhra Medical College, Visakhapatnam.

${ }_{4}^{4}$ Postgraduate Student, Department of ENT, Andhra Medical College, Visakhapatnam.

\section{ABSTRACT}

\section{BACKGROUND}

Epistaxis is the commonest emergency we come across in ENT outpatient department affecting upto $60 \%$ of the general population in their lifetimes, with $6 \%$ of the cases requiring medical attention. Epistaxis is defined as bleeding from nose even though the actual meaning of the term means bleeding from above. Epistaxis is a sign not a disease. It can occur in any patient irrespective of sex and age.

Aims and objectives-

1. To assess the commonest cause and other diseases which produces epistaxis.

2. To assess the different methods used to control epistaxis.

\section{MATERIALS AND METHODS}

The study was conducted in a Tertiary Referral Government ENT Hospital, Visakhapatnam in Andhra Pradesh state for a period of 1 year that is from July 2016 to June 2017, in 383 patients attended with complaint of epistaxis either with a single episode 275 or multiple episodes 108. These patients were distributed on sex and age variation. They were categorised into groups depending upon the clinical, pathological diagnosis and on the basis of modalities of treatment.

\section{RESULTS}

In this study, males were 59.5\% (228) and females 40.5\%. (155). With M: F ratio of 1.47: 1. Age group of 0-10 years with 51.7\% (198) was the most common age affected with epistaxis. The second most common age group was the 31-40 years age. Epistaxis due to trauma to the Little's area 142 (37.07\%) evolved as a commonest aetiology. Later were rhinosinusitis 108 (28.19\%), hypertension $48(12.53 \%)$, trauma 35 (9.13\%), DNS with spur $14(3.65 \%)$. Bleeding from the septum particularly Little's area in children, and from the lateral wall over the posterior aspect in adults was the commonest area of bleed. Conservative medical management $123(32.1 \%)$ was mostly used to control the epistaxis. Next line of management were local cauterization and anterior nasal packing.

\section{CONCLUSION}

Epistaxis was common in males than females. Bleeding from Little's area of the septum was the commonest cause of epistaxis in children and also, in the total population. The next causes were rhinosinusitis and hypertension in which epistaxis arises from the lateral wall of the nose in adults. Conservative medical management was the commonest mode of treatment in most of the cases.

\section{KEYWORDS}

Epistaxis, Aetiology, Nasal Packing, Hypertension.

HOW TO CITE THIS ARTICLE: Prasad TVSSNL, Rambabu P, Rao SS, et al. Epistaxis- an analytical study in tertiary referral hospital. J. Evolution Med. Dent. Sci. 2018;7(08):989-992, DOI: 10.14260/jemds/2018/226

\section{BACKGROUND}

Epistaxis is the commonest emergency we come across in ENT outpatient department affecting upto $60 \%$ of the general population in their lifetimes, with $6 \%$ of the cases requiring medical attention.

Epistaxis is defined as bleeding from nose even though the actual meaning of the term means bleeding from above. Epistaxis is a sign not a disease. It can occur in any patient irrespective of sex and age. There are peaks in incidence for patients both younger than 10 years old and older than 40 years.

'Financial or Other Competing Interest': None.

Submission 11-01-2018, Peer Review 07-02-2018,

Acceptance 12-02-2018, Published 19-02-2018.

Corresponding Author:

Dr. P. Rambabu,

D. No. 20-99-76,

Jabbar Thota, Near AVN College,

Visakhapatnam-530001.

E-mail:potti_rambabu@yahoo.com

DOI: $10.14260 /$ jemds $/ 2018 / 226$

\section{(c) $(1) \odot$}

Normally epistaxis from anterior part is more common in children due to nasal picking over Kiesselbach's area and in adults from posterior part of the nose due to hypertension. The causes of epistaxis include both systemic and local factors. Trauma due to road traffic and other accidents is increasing day by day. Other causes like fibroangioma, bleeding polypus, pyogenic granuloma, DNS with spur, rhinosinusitis, granulomatous diseases like rhinosporidiosis, Wegener's granulomatosis, tumours like juvenile nasopharyngeal angiofibroma, esthesioblastoma, carcinoma of nose, paranasal sinuses and nasopharynx. Systemic diseases like hypertension, liver and kidney disorders and blood dyscrasias can also produce epistaxis. Hence the epistaxis diagnosis and management are very much essential part of learning for an ENT surgeon.

In olden days cauterization with silver nitrate and trichloro acetic acid, anterior nasal packing and post-nasal packing were primary mode of treatment but now inflation of Foleys catheter and different balloon catheters, Merocel packing, endoscopic cauterization and ligation made the management of epistaxis easy. Which occurs due to local 
causes like trauma, infection, FB, neoplasm and DNS, general causes like Cardio vascular disorders, liver, kidney and blood dyscrasias.

\section{Design of Study}

Retrospective descriptive study.

\section{MATERIALS AND METHODS}

The Retrospective descriptive study was conducted in a Government ENT Hospital. Visakhapatnam, which is a Tertiary Referral Hospital in state of Andhra Pradesh. The study period was about 1 year that is from JULY 2016 to JUNE 2017. Out of about 38,500 out patients, 383 patients attended with complaints of epistaxis. In the above, 275 patients attended with a single episode of epistaxis and 108 were with recurrent episodes.

These patients were distributed according to the gender and spread into different groups on the basis of their age variation. Later they were categorised into thirteen groups depending upon their clinical and pathological diagnosis i.e. bleeding from Little's area, rhinosinusitis, DNS with spur, foreign body of nose, fibroangioma, traumatic injuries, hypertension, juvenile nasoangiofibroma, rhinosporidiosis, esthesioblastoma, carcinoma of nose and PNS, carcinoma nasopharynx, hereditary telangiectasia.

Once again, they are divided into eight, 8 sections on the basis of mode of treatment like conservative medical management, cauterization (chemical or electro surgical), anterior nasal packing, posterior nasal packing, septal surgery, sinus surgery, other different surgical measures and irradiation applied according to the aetiology.

\section{Inclusion Criteria}

All the patients with epistaxis attended as an outpatient and inpatient.

\section{Exclusion Criteria}

Iatrogenic epistaxis. Epistaxis due to irradiation. Epistaxis due to liver, renal and blood dyscrasias. Idiopathic epistaxis.

\section{RESULTS}

\begin{tabular}{|c|c|c|c|}
\hline Sl. No. & Sex & Number & $\begin{array}{c}\text { Percentage } \\
\text { (\%) }\end{array}$ \\
\hline 1 & Male & 228 & $59.5 \%$ \\
\hline 2 & Female & 155 & $40.5 \%$ \\
\hline \multicolumn{3}{|c|}{ Incidence in Gender } \\
\hline
\end{tabular}

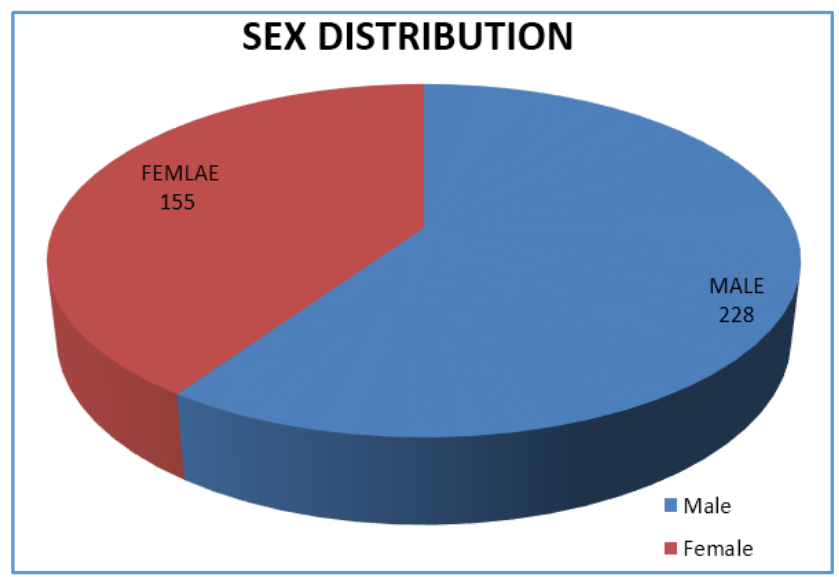

In this study epistaxis found to be male preponderance $59.5 \%$ (228) when compared to female $40.5 \%$ (155).

Male female ratio was 1.47: 1

\begin{tabular}{|c|c|c|c|}
\hline Sl. No. & Age & Number of Patients & (\%) \\
\hline 1 & $0-10$ & 198 & $51.7 \%$ \\
\hline 2 & $11-20$ & 36 & $9.4 \%$ \\
\hline 3 & $21-30$ & 37 & $9.6 \%$ \\
\hline 4 & $31-40$ & 41 & $10.8 \%$ \\
\hline 5 & $41-50$ & 31 & $8.1 \%$ \\
\hline 6 & $51-60$ & 36 & $9.4 \%$ \\
\hline 7 & $61-70$ & 4 & $1 \%$ \\
\hline Total & \multicolumn{3}{|c|}{ Age Distribution } \\
\hline \multicolumn{4}{|c|}{} \\
\hline
\end{tabular}

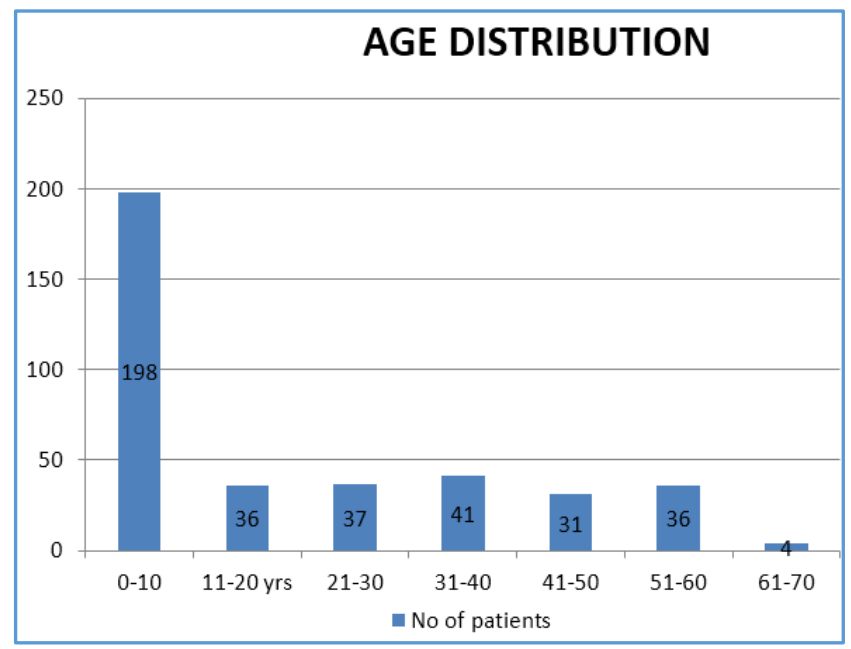

0-10 years age group $51.7 \%$ (198) was the most common age group presented with epistaxis. The second most common was the $31-40$ years age group $10.8 \%$ (41) and the least affected was 61-70 yrs., $1 \%$ (4).

\begin{tabular}{|c|c|c|c|c|}
\hline Cause & No. Cases & (\%) & Male & Female \\
\hline Littles area & 142 & $37.07 \%$ & 86 & 56 \\
\hline Trauma & 35 & $9.13 \%$ & 22 & 13 \\
\hline DNS with spur & 14 & $3.65 \%$ & 8 & 6 \\
\hline Foreign body & 9 & $2.34 \%$ & 5 & 4 \\
\hline Rhinosinusitis & 108 & $28.19 \%$ & 58 & 50 \\
\hline Hypertension & 48 & $12.53 \%$ & 32 & 16 \\
\hline Fibroangioma & 13 & $3.39 \%$ & 7 & 6 \\
\hline $\begin{array}{c}\text { Juvenile } \\
\text { nasopharyngeal } \\
\text { angiofibroma }\end{array}$ & 3 & $0.78 \%$ & 3 & 0 \\
\hline $\begin{array}{c}\text { Hereditary } \\
\text { telangiectasia }\end{array}$ & 2 & $0.52 \%$ & 0 & 2 \\
\hline Rhinosporidiosis & 2 & $0.52 \%$ & 2 & 0 \\
\hline Esthesioneuroblastoma & 1 & $0.26 \%$ & 0 & 1 \\
\hline $\begin{array}{c}\text { Carcinoma of nose and } \\
\text { PNS }\end{array}$ & 1 & $0.26 \%$ & 1 & 0 \\
\hline $\begin{array}{c}\text { Nasopharyngeal } \\
\text { carcinoma }\end{array}$ & 3 & $0.78 \%$ & 2 & 1 \\
\hline $\begin{array}{c}\text { Total } \\
\text { Causes of epistaxis }\end{array}$ \\
\hline \multicolumn{2}{|c|}{$\mathbf{3 8 3}$} & $\mathbf{2 2 8}$ & $\mathbf{1 5 5}$ \\
\hline
\end{tabular}

Epistaxis due to trauma to the Little's area 142 (37.07\%) evolved as a commonest aetiology. Next were rhinosinusitis 108 (28.19\%), hypertension 48 (12.53\%), trauma 35 (9.13\%), DNS with spur 14 (3.65\%), fibroangioma 13 $(3.39 \%)$, foreign body nose 9 (2.34\%), juvenile 
nasopharyngeal fibroma $3(0.78 \%)$, carcinoma nasopharynx $3 \quad(0.78 \%)$, rhinosporidiosis $2 \quad(0.52 \%)$, hereditary telangiectasia $2(0.52 \%)$ in descending order. The least common observed pathology were esthesioblastoma 1 $(0.26 \%)$ and carcinoma of nose with PNS in $1(0.26 \%)$ patient each.

\begin{tabular}{|c|c|c|}
\hline Site & No. of Cases & Percentage (\%) \\
\hline $\begin{array}{c}\text { Septum (ant and } \\
\text { post) }\end{array}$ & 182 & $47.5 \%$ \\
\hline Lateral wall & 191 & $49.9 \%$ \\
\hline Floor & 6 & $1.6 \%$ \\
\hline Roof & 1 & $0.2 \%$ \\
\hline Nasopharynx & 3 & $0.8 \%$ \\
\hline \multicolumn{3}{|c|}{ Site of bleed } \\
\hline
\end{tabular}

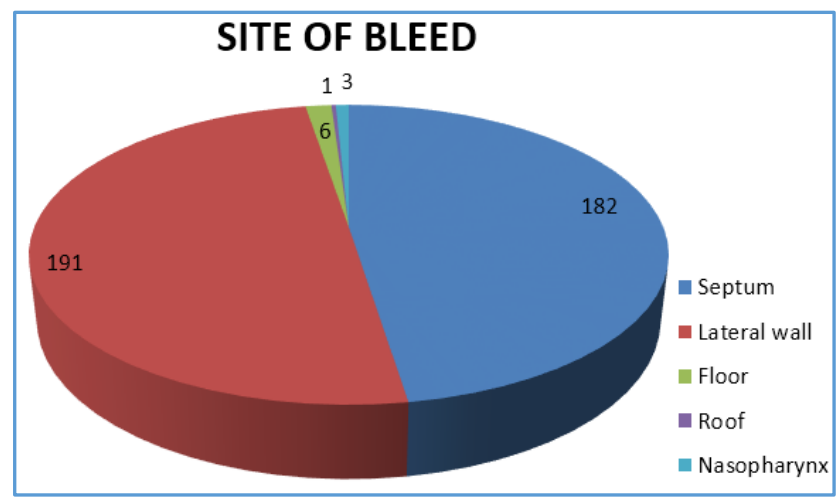

Bleeding from the septum particularly Little's area in children is the commonest identified aetiology. Bleeding from the lateral wall and particularly from the posterior aspect in adults was recognized as commonest area of epistaxis.

\begin{tabular}{|c|c|c|}
\hline Type of Treatment & No. of Cases & (\%) \\
\hline Conservative medical treatment & 123 & $32.1 \%$ \\
\hline $\begin{array}{c}\text { Local cauterization } \\
\text { (chem./Electro) }\end{array}$ & 52 & $13.5 \%$ \\
\hline Anterior nasal packing & 53 & $13.8 \%$ \\
\hline Posterior nasal packing & 12 & $3.1 \%$ \\
\hline Septal surgery & 14 & $3.7 \%$ \\
\hline $\begin{array}{c}\text { Anterior nasal packing with Sinus } \\
\text { surgery }\end{array}$ & 108 & $28.2 \%$ \\
\hline Other surgical measures & 17 & $4.4 \%$ \\
\hline Radiation & 4 & $1 \%$ \\
\hline \multicolumn{2}{|c|}{ Modalities of treatment } \\
\hline \multicolumn{2}{|c}{} \\
\hline
\end{tabular}

Out of the different treatment modalities the conservative medical treatment $123(32.1 \%)$ was mostly used to control the epistaxis. The second most common treatment applied was anterior nasal packing with sinus surgery 108 (28.2\%). Next the local cauterization with chemicals and electrical cautery in $52(13.5 \%)$ and only anterior nasal packing in 53 (13.8\%) were almost equally used. Radiation was used in 4 cases $(1 \%)$.

\section{DISCUSSION}

The commonest cause of epistaxis in children evolved as the nasal pricking over the Little's area of septum ${ }^{1}$ and later is the Rhinosinusitis. The male children were being more naughty and aggressive, which contributed to the male dominance in epistaxis. Hypertension with smoking and alcohol consumption which is more common in males, also resulted male preponderance $59.5 \%$ (228) than females $40.5 \%$ (155). Male female ratio ${ }^{2}$ is $1.47: 1$. Our results are almost similar with Saurabh Varshney et al, 2005 results.

$51.7 \%$ (198) patients were present in the most common age group of $0-10$ years, as the epistaxis due to prick or trauma to the little's area was more common cause in children.3,4,5 The second most common age group affected was the $31-40$ years $10.8 \%$ (41) as it includes trauma and other aetiology. In the total adult population, all the age groups were almost equally suffered with epistaxis due to hypertension, rhinosinusitis and trauma. The least suffered age group was $61-70$ years $1 \%$ (4).

The commonest cause of epistaxis in adults was the hypertension ${ }^{6}$ and mostly seen in the $4^{\text {th }}, 5^{\text {th }}$ and $6^{\text {th }}$ decades of age which was similar to the study done by Kalpana Sharma et al, 2015 reports. In children bleeding was primarily from the Little's area of the septum, later from the lateral wall and floor of the vestibule. In adults it was more common from the lateral wall of the nose particularly behind the posterior end of the middle turbinate i.e., from sphenopalatine foramen area.

Among the total patients of epistaxis, trauma to the Little's area $142(37.07 \%)$ stood first and raised to be the commonest aetiology. The second commonest cause was the rhinosinusitis 108 (28.19\%) due to increased number of patients suffering from allergy and super added secondary infection. Neglected hypertension $48(12.53 \%)$ was the third most common identified cause. Trauma 35 (9.13\%) and DNS with spur 14 (3.65\%) were less common causes which need corrective surgery. Further in descending order observed were fibroangioma 13 (3.39\%), foreign body nose 9 (2.34\%), juvenile nasopharyngeal fibroma 3 (0.78\%), carcinoma nasopharynx 3 (0.78\%), rhinosporidiosis 2 (0.52\%), hereditary telangiectasia $2(0.52 \%)$. The rarely diagnosed esthesioblastoma $1(0.26 \%)$ and carcinoma of nose with PNS $1(0.26 \%)$, were the least commonly seen pathology.

Most of the epistaxis were primarily managed with conservative medical management ${ }^{2,} 7$ in 123 (32.1\%) patients, later was the anterior nasal packing with sinus surgery in 108(28.2\%), only anterior nasal packing3, 8 in $53(13.8 \%)$ with either cotton wick or ribbon gauze or Merocel and cauterization with chemical or electric cautery $52(13.5 \%)$ which were almost equally used in the management. Rarely the post nasal packing with regular post nasal pack or Foley's catheter, 12 (3.1\%) was used.

The epistaxis with rhinosinusitis was managed by performing functional endoscopic sinus surgery ${ }^{9}$ in 108 (28.2\%) patients. Epistaxis due to deviated nasal septum with spur was brought under control by septoplasty or spurectomy in $14(3.7 \%)$. In those patients, carcinoma of nose, para nasal sinuses and nasopharynx were managed by irradiation 4 (1\%) by referring to radiotherapy department, was the least common modality used.

\section{CONCLUSION}

In the study, males were found to be affected more than females in both children and adult population. Bleeding from Little's area of the septum was found to be the commonest cause of epistaxis in children of the age $0-10$ years and also in the total population. The second most common cause was the rhinosinusitis, later was hypertension which is commonly seen in adult patients where epistaxis arises from the lateral 


\section{Jemds.com}

wall of the nose. Conservative medical management was the commonest mode of treatment in most of the cases. Next was the anterior nasal packing and rarely post nasal packing was used. The other pathologies including rhinosinusitis, deviated nasal septum, benign and malignant lesions which are managed later with surgery and irradiation.

\section{REFERENCES}

[1] Pope LER, Hobbs CGL. Epistaxis: an update on current management. Postgrad Med J 2005;81(955):309-14.

[2] Varshney S, Saxena RK. Epistaxis: a retrospective clinical study. Indian Journal of Otolarygology and Head and Neck Surgery 2005;57(2):125-9.

[3] Gilyoma JM, Chalya PL. Etiological profile and treatment outcome of epistaxis at a tertiary care hospital in Northwestern Tanzania: a prospective review of 104 cases. BMC Ear, Nose and Throat Disorders 2011;11:8.

\section{Original Research Article}

[4] Schlosser RJ. Clinical practice. Epistaxis. New England Journal of Medicine 2009;360(8):784-9.

[5] Bernius M, Perlin D. Pediatric ear, nose and throat emergencies. Pediatr Clin North Am 2006;53(2):195214.

[6] Sharma K, Kumar S, Islam T. A retrospective study on etiology and management of epistaxis in elderly patients. Archives of Medicine and Health Sciences 2015;3(2):234-8.

[7] Monux A, Tomas M, Kaiser C, et al. Conservative management of epistaxis. J Laryngol Otol 1990;104(11):868-70.

[8] Pollice PA, Yoder MG. Epistaxis: a retrospective review of hospitalized patients. Otolaryngol Head Neck Surg 1997;117(1):49-53.

[9] Kennedy DW, Zinreich SJ, Rosenbaum AE, et al. Functional endoscopic sinus surgery. Theory and diagnostic evaluation. Arch Otolaryngol 1985;111(9):576-82. 